\title{
Underage drinking in Brazil: findings from a community household survey
}

\author{
Coral Rakovski, ${ }^{1}$ iD Taiane de Azevedo Cardoso, ${ }^{2}$ Jurema Corrêa da Mota, ${ }^{3}$ Francisco I. Bastos, ${ }^{3}$ \\ Flavio Kapczinski, ${ }^{1,2,4,5,6}$ Raquel Brandini De Boni ${ }^{3}$ iD \\ ${ }^{1}$ Neuroscience Graduate Program, McMaster University, Hamilton, ON, Canada. ${ }^{2}$ Department of Psychiatry and Behavioural Neurosciences, \\ McMaster University, Hamilton, ON, Canada. ${ }^{3}$ Instituto de Comunicação e Informação Científica e Tecnológica em Saúde, Fundação Oswaldo \\ Cruz, Rio de Janeiro, RJ, Brazil. ${ }^{4}$ Programa de Pós-Graduação em Psiquiatria e Ciências do Comportamento, Departamento de Psiquiatria, \\ Faculdade de Medicina, Universidade Federal do Rio Grande do Sul, Porto Alegre, RS, Brazil. ${ }^{5}$ Centro de Pesquisa Experimental, Laboratório \\ de Psiquiatria Molecular, Hospital de Clínicas de Porto Alegre (HCPA), Porto Alegre, RS, Brazil. ${ }^{6}$ Centro de Pesquisa Clínica, Laboratório de \\ Psiquiatria Molecular, HCPA, Porto Alegre, RS, Brazil.
}

\begin{abstract}
Objectives: Previous studies have estimated the 30-day prevalence of alcohol use to be approximately $21 \%$ among youth in Brazil, despite the legal drinking age of 18 years. The present study aimed to determine the prevalence of underage drinking and its associated factors among adolescents in Brazil.

Methods: The 3rd National Survey on Drug Use by the Brazilian Population (III Levantamento Nacional sobre o Uso de Drogas pela População Brasileira) is a nationwide, multi-stage, probabilitysample household survey. Herein, youth between the ages of 12-17 years were included. Lifetime and 12-month alcohol use prevalence were estimated. Factors associated with 12-month alcohol use were evaluated through multivariate analysis considering survey weights and design.

Results: Overall, 628 youth were interviewed. Estimated lifetime and 12-month alcohol use were $34.3 \%$ (standard error $[S E]=1.9$ ) and $22.2 \%(S E=1.7)$, respectively. Factors associated with 12-month drinking were: other/no religion vs. Christianity; living in rural vs. urban areas; self-reported diagnosis of depression vs. no self-reported depression; lifetime tobacco use vs. no history of tobacco use; and any illicit drug use vs. no history of illicit drug use.

Conclusion: Considering that alcohol use is a major risk factor for early death among Brazilian youth, our findings highlight the importance of preventative measures to reduce underage drinking.
\end{abstract}

Keywords: Alcohol; underage drinking; population-based surveys; mental health; Brazil

\section{Introduction}

Underage alcohol use is a public health concern, resulting in several adverse consequences among adolescents. ${ }^{1}$ According to data from the United States, the lifetime prevalence of alcohol use is about $60 \%$ for adolescents by the end of high school, ${ }^{2}$ despite a legal drinking age of 21 years or older. Interestingly, the past-30-day prevalence of underage drinking in the United States decreased significantly from 2002 to 2019 (percent decrease by age group: $41.1 \%$ for individuals aged 16 $17 ; 54.7 \%$ for individuals aged $14-15$; and $61.9 \%$ for individuals aged 12-13) based on the 2019 National Survey on Drug Use and Health (NSDUH). ${ }^{3}$ Additionally, a systematic review found that the mean prevalence of current alcohol use is approximately $35 \%$ among Brazilian adolescents between the ages of 10 to 19 years. ${ }^{4}$ Alcohol consumption by adolescents has been associated with

Correspondence: Raquel Brandini De Boni, Instituto de Comunicação e Informação Científica e Tecnológica em Saúde, Fundação Oswaldo Cruz, Avv. Brasil, 4365, Pavilhão Haity Moussatche, sala 229, CEP 21040-360, Rio de Janeiro, RJ, Brazil.

E-mail: raquel.boni@icict.fiocruz.br

Submitted Jul 01 2021, accepted Aug 27 2021, Epub Dec 152021. negative outcomes including deficits in cognition and brain development, poor relationships with others, poor academic achievement, criminality, as well as death. ${ }^{1,5-8}$ Evidence also suggests that components of social context, such as peer influences and parenting factors, especially during early adolescence, have an influence on later drinking behaviors and on alcohol-related problems. ${ }^{9}$ Importantly, prior findings have also indicated that alcohol use during adolescence is a predictor of alcohol use disorder (AUD) and substance use disorder. ${ }^{9,10}$

It is well known that, during adolescence, the brain undergoes numerous neurodevelopmental changes and continues to develop until young adulthood, causing the brain to be especially vulnerable throughout this period. $^{5,11}$ Adolescents are particularly susceptible to engagement in high-risk behaviors, such as underage drinking, because the prefrontal cortex, which has a primary role in decision making, is still undergoing

How to cite this article: Rakovski C, Cardoso TA, da Mota JC Bastos FI, Kapczinski F, De Boni RB, et al. Underage drinking in Brazil: findings from a community household survey. Braz $J$ Psychiatry. 2022;44:257-263. http://dx.doi.org/10.1590/1516-44462021-2103 
maturation at this stage. ${ }^{12}$ Alcohol use during adolescence has been associated with changes in brain structure and function, as well as cognitive deficits. ${ }^{5}$ Furthermore, adolescents commonly engage in binge drinking, which is associated with a greater likelihood of being diagnosed with an AUD and additional neurobiological changes (e.g., decreased cortical thickness in the frontal lobe and cingulate; decreased grey-matter volume in the frontal lobe, temporal lobe, and cerebellum; various changes in task activation across specific regions of the brain). ${ }^{13}$ Binge drinking refers to the consumption of approximately five or more alcohol beverages for males and four or more alcohol beverages for females during a 2-hour period. ${ }^{13,14}$ Together, these findings reinforce the importance of studying this population to prevent the negative outcomes that arise from alcohol consumption during adolescence.

Notably, a study in Brazil that analyzed data from almost 75,000 adolescents between the ages of 12 and 17 found that $21 \%$ consumed alcohol within the past 30 days, despite the current legal drinking age of 18 years or older in the country. ${ }^{15}$ While these results are concerning, there are a lack of studies assessing the lifetime and 12-month prevalence of alcohol use among Brazilian adolescents, as well as potential contributing factors.

Thus, the aim of the present study was to estimate the prevalence of underage drinking and its associated factors among a nationally representative population of adolescents in Brazil.

\section{Methods}

The 3rd National Survey on Drug Use by the Brazilian Population (III Levantamento Nacional sobre o Uso de Drogas pela População Brasileira) is a nationwide, multistage, probability-sample household survey. The sample included 16,273 Brazilians aged 12 to 65 years, living in urban and/or rural areas who were interviewed between 2015 and 2016. Native individuals living in indigenous villages, persons deprived of liberty, and individuals with physical or mental disabilities that precluded answering the interview questions were not eligible. ${ }^{16-19}$ Details regarding sampling, questionnaires, data collection, data entry, and handling of non-response are fully available elsewhere. $^{20}$

\section{Participants}

In the present analysis, 628 youth between the ages of 12 and 17 years were included, representing 20 million individuals of this age after proper weighting, as briefly described elsewhere. ${ }^{17}$

\section{Outcome}

The main outcome was underage drinking, assessed by self-reported alcohol use in the preceding 12 months. In Brazil, since 2015, it is a crime to "sell, provide, serve, minister, or deliver" alcoholic beverages to youth under the age of 18 years. ${ }^{21}$

\section{Variables}

Demographic variables were collected using questions from the Brazilian Demographic census, ${ }^{22}$ and included: sex at birth (male vs. female); sexual orientation (heterosexual, homosexual, other/do not want to answer); color/ race (white, black, mixed, other); school attendance (yes, not anymore); religion (Catholic, Christian, none, other); having a steady partner (yes, no); number of children (none, one or more); geographic macro-region of residence (North/Northeast, Southeast/South, and CenterWest); and living in urban vs. rural areas.

General health variables included: self-rated health (very good/good, fair/do not know, and very poor/poor) ${ }^{23}$; and reporting 12-month treatment and/or diagnosis for diabetes, heart disease, hypertension, asthma, renal disease, depression, anxiety, or bipolar disorder.

Lifetime substance use was aggregated as prescription medication used to "feel high" (benzodiazepines, anticholinergics, barbiturates, and opioids), tobacco use, and illicit drug use (inhalants, marijuana, cocaine/crack, ecstasy).

Alcohol-related problems included binge drinking in the previous 30 days (defined as the consumption of approximately five or more alcohol beverages for males and four or more for females within a 2-hour period), ${ }^{14}$ and 12-month report of the following: having used alcohol in situations representing physical risk (such as driving, swimming, piloting motorcycles, operating machines, etc.); and having personal problems due to alcohol use. In addition, individuals were asked whether, in the previous 12 months, they had done any of the following after using alcohol: driven, had an argument, destroyed something, hurt themselves, been beaten, hurt someone, been threatened, had difficulties fulfilling obligations at school/work, left school, or stolen something.

\section{Statistical analysis}

Prevalence, standard error (SE), and estimated population were calculated for selected demographic variables, general health (self-rated and selected medical conditions), lifetime substance use, and alcohol-related problems. Prevalence and SE were estimated for all variables stratified by underage drinking and compared using Pearson's chi-square test with Rao-Scott adjustment. ${ }^{24}$ Variables presenting a p-value $<0.20$ at the bivariate test were considered for the multivariable regression model. The final model was fitted considering the backward method, maintaining those variables with a significance level of $5 \%$, with the exception of sex, age, and self-rated health, which were kept in the model by epidemiological criteria. All the analyses considered sample weights, design effect, and weight calibration. Analyses were performed in $\mathrm{R}$ version 3.5.0 using the "survey" and "surveyer" packages. ${ }^{25}$

\section{Ethics statement}

The 3rd National Survey on Drug Use by the Brazilian Population was approved by an ethics committee of 
Fundação Oswaldo Cruz (Fiocruz; CAAE \# 35283814. 4.0000.5241).

\section{Results}

This study included 628 youth between the ages of 12-17 years, representing 20 million individuals of this age in Brazil. The sample characteristics are described in Table 1. Briefly, $56 \%$ of the study participants were male, $90 \%$ attended school, and $86 \%$ reported their overall health as very good/good. Anxiety and asthma were the most common self-reported diagnoses, with a prevalence of 8 and $10 \%$ respectively. Alcohol, tobacco, and marijuana were the substances most frequently reported for lifetime use, by 34.3 (SE = 1.9), $6.3(\mathrm{SE}=1.1)$, and $3.3 \%$ $(\mathrm{SE}=0.8)$ of the participants, respectively.

Underage drinking was estimated at $22.2 \%(\mathrm{SE}=1.7)$. Of those who reported underage drinking, 22.7\% (SE = 4.1) reported binge drinking and $9.4 \%(S E=2.6)$ had an argument after consuming alcohol. Factors associated with underage drinking in the bivariate analysis were: not attending school $(p=0.01)$; not being Christian $(p<$ $0.001)$; living in a rural area $(p<0.001)$; poor self-rated health $(p<0.001)$; depression $(p<0.001)$; bipolar disorder ( $p<0.001)$; lifetime tobacco use $(p<0.001)$; and lifetime use of any illicit drug $(p<0.001)$ (Table 1).

Table 2 shows the final adjusted model. Specifically, the main risk factors for 12-month alcohol use were: residing in rural areas compared to urban areas (adjusted odds ratio $[\mathrm{AOR}] 2.29,95 \%$ confidence interval $[95 \% \mathrm{Cl}]$ 1.30-4.04); self-reporting a diagnosis of depression (AOR 8.79, 95\% $\mathrm{Cl} 1.03-74.72$ ); lifetime tobacco use (AOR 13.27, $95 \% \mathrm{Cl} 5.14-34.27$ ); and any illicit drug use (AOR $3.40,95 \% \mathrm{Cl} 1.03-11.18$ ). Importantly, being Christian was a protective factor in comparison to other/no religion (AOR $2.55,95 \% \mathrm{Cl} 1.52-4.29$ ).

Figure 1 shows that those with 12-month alcohol use had a greater prevalence of alcohol-related problems in comparison to the general adolescent population, as follows: binge drinking ( 22.7 vs. $5 \%$, respectively); risk of physical injury (3.5 vs. $0.8 \%$, respectively); relationship problems (7.1 vs. $1.6 \%$, respectively); driving under the influence of alcohol ( $2.1 \mathrm{vs.} 0.5 \%$, respectively); having an argument (9.4 vs. $2.1 \%$, respectively); destruction of objects (1.2 vs. $0.3 \%$, respectively); self-harm (2.2 vs. $0.5 \%$, respectively); being beaten ( 1.7 vs. $0.4 \%$, respectively); hurting someone else (2.8 vs. $0.6 \%$, respectively); and difficulty fulfilling one's obligations (2.2 vs. $0.5 \%$, respectively).

\section{Discussion}

The present study found a lifetime prevalence of $34.3 \%$ and a 12-month prevalence of $22.2 \%$ for alcohol use among youth between the ages of 12 and 17 years in Brazil. The prevalence of underage drinking was greater among individuals residing in rural areas as compared to urban areas, individuals self-reporting depression as compared to those that did not self-report depression, individuals with lifetime tobacco use as compared to those with no history of tobacco use, and individuals with any illicit drug use as compared to those with no history of illicit drug use. Interestingly, being Christian was associated with a lower prevalence of underage drinking as compared to individuals who self-reported other/no religion. Furthermore, those who consumed alcohol within the last 12 months had a higher prevalence of binge drinking, physical injury, relationship problems, driving under the influence of alcohol, having an argument, destruction of objects, self-harm, being beaten, hurting someone else, and difficulty fulfilling one's obligations as compared to the overall population.

According to the $2019 \mathrm{NSDUH}$, the 12-month prevalence of alcohol use among adolescents aged 12-17 years in the United States was $21.2 \% .^{26}$ These findings are similar to those of the current study, which found a 12month prevalence of $22.2 \%$ for alcohol use by youth of the same age range in Brazil. A previous systematic review found a mean prevalence of $35 \%$ (23 to $67 \%$ ) for current alcohol use among Brazilian adolescents, which is also similar to the findings of the current study. ${ }^{4}$ In contrast, Canadian survey results from 2018-2019 found a 12-month prevalence of $44 \%$ for alcohol use among adolescents from grades $7-12 .{ }^{27}$

Prior studies have demonstrated significant associations between specific sociodemographic characteristics and an increased prevalence of alcohol use among adolescents, including residing in rural areas as well as non-religiosity. ${ }^{28,29} \mathrm{~A}$ longitudinal study also found that adolescent alcohol use was a predictor of subsequent illicit drug abuse. ${ }^{30}$ Interestingly, a meta-analysis showed that AUD was a predictor of depression. ${ }^{31} \mathrm{~A}$ previous study in Brazil found a significant relationship between alcohol use and physical violence for adolescent males between the ages of 13 and 15 years. ${ }^{32}$ Underage alcohol consumption is also linked to binge drinking, which has concerning associations with alcohol-related injury, alcohol-related physical/sexual assault, and road traffic collisions. ${ }^{33}$ Lastly, the current study indicated that being Christian is a protective factor against underage drinking, which has been supported by other studies showing that religiosity protects against alcohol use in adolescents. ${ }^{29}$ Unfortunately, the small sample size precludes the assessment of the putative protective effect of other religions and denominations on underage drinking and harmful/dependent use of alcohol in a broader sense. Overall, the findings of prior studies are consistent with the main results of our present study, indicating that various sociodemographic characteristics, illicit substance use, and medical conditions are factors associated with adolescent alcohol consumption as well as its related problems.

The high prevalence of alcohol use and alcohol-related problems among Brazilian adolescents that we found in the present study highlights the importance of implementing preventative measures against underage drinking in this population. This is particularly urgent considering that alcohol consumption among adolescents has been linked to functional and cognitive impairments such as deficits in learning, executive functioning, attention, and memory. ${ }^{5,6}$ Notably, underage drinking can impact the development of the adolescent brain, resulting in the aforementioned 
Table 1 Sociodemographic and clinical characteristics and their association with underage drinking among youth between the ages of $12-17$ years, Brazil, 2015

\begin{tabular}{|c|c|c|c|c|c|c|c|c|}
\hline \multirow[b]{3}{*}{ Variables } & \multirow{2}{*}{\multicolumn{3}{|c|}{ Overall }} & \multicolumn{4}{|c|}{ Underage drinking } & \multirow[b]{3}{*}{ p-value } \\
\hline & & & & \multicolumn{2}{|c|}{ Yes } & \multicolumn{2}{|c|}{ No } & \\
\hline & Estimated population $(\mathrm{N})$ & $\%$ & SE & $\%$ & SE & $\%$ & SE & \\
\hline Sex & & & & & & & & 0.61 \\
\hline Male & $11,436,244$ & 56.4 & 2.7 & 58.7 & 4.8 & 55.7 & 3.2 & \\
\hline Female & $8,840,14$ & 43.6 & 2.7 & 41.3 & 4.8 & 44.3 & 3.2 & \\
\hline Sexual orientation & & & & & & & & 0.34 \\
\hline Heterosexual & $19,599,154$ & 96.7 & 0.9 & 95.2 & 1.6 & 97.1 & 1.0 & \\
\hline Homosexual (gay or lesbian) & 99,640 & 0.5 & 0.2 & 1.1 & 0.8 & 0.3 & 0.2 & \\
\hline Other/do not know/do not want to answer & 577,591 & 2.8 & 0.9 & 3.6 & 1.3 & 2.6 & 1.0 & \\
\hline Skin color & & & & & & & & 0.57 \\
\hline White & $7,145,829$ & 35.2 & 2.4 & 37.4 & 5.0 & 34.6 & 2.5 & \\
\hline Black & $2,014,357$ & 9.9 & 1.3 & 8.4 & 2.3 & 10.4 & 1.7 & \\
\hline Mixed & $10,872,106$ & 53.6 & 2.3 & 54.1 & 5.2 & 53.5 & 2.4 & \\
\hline Other & 244,093 & 1.2 & 0.6 & 0.0 & 0.0 & 1.5 & 0.8 & \\
\hline Attends school & & & & & & & & 0.01 \\
\hline Yes & $18,247,771$ & 90.0 & 1.4 & 82.5 & 3.7 & 92.1 & 1.7 & \\
\hline Not anymore & $2,028,614$ & 10.0 & 1.4 & 17.5 & 3.7 & 7.9 & 1.7 & \\
\hline \multicolumn{9}{|l|}{ Religion } \\
\hline Christian & $6,609,932$ & 32.6 & 2.7 & 18.0 & 3.7 & 36.8 & 3.1 & 0.00 \\
\hline Other & $13,666,454$ & 67.4 & 2.7 & 82.0 & 3.7 & 63.2 & 3.1 & \\
\hline Stable partner & & & & & & & & 0.55 \\
\hline Yes & 361,130 & 1.8 & 0.8 & 2.6 & 1.3 & 1.5 & 1.1 & \\
\hline No & $19,915,255$ & 98.2 & 0.8 & 97.4 & 1.3 & 98.5 & 1.1 & \\
\hline Number of children & & & & & & & & 0.05 \\
\hline None & $20,018,134$ & 98.7 & 0.8 & 97.4 & 1.2 & 99.1 & 0.3 & \\
\hline One & 258,251 & 1.3 & 0.4 & 2.6 & 1.2 & 0.9 & 0.3 & \\
\hline Region & & & & & & & & 0.56 \\
\hline North-Northeast & $8,962,864$ & 44.2 & 3.3 & 45.2 & 5.3 & 43.9 & 3.5 & \\
\hline South-Southeast & $9,420,721$ & 46.5 & 3.4 & 47.8 & 5.1 & 46.1 & 3.7 & \\
\hline Center-West & $1,892,800$ & 9.3 & 1.6 & 7.0 & 1.9 & 10.0 & 1.8 & \\
\hline Urban vs. rural & & & & & & & & 0.00 \\
\hline Urban & $16,318,779$ & 80.5 & 2.3 & 70.2 & 4.9 & 83.4 & 2.4 & \\
\hline Rural & $3,957,606$ & 19.5 & 2.3 & 29.8 & 4.9 & 16.6 & 2.4 & \\
\hline Self-rated health & & & & & & & & 0.11 \\
\hline Very good/good & $17,468,645$ & 86.1 & 1.9 & 90.8 & 2.7 & 84.4 & 2.3 & \\
\hline Fair/poor/very poor & $2,807,740$ & 13.85 & 1.9 & 9.2 & 2.7 & 15.2 & 2.3 & \\
\hline \multicolumn{9}{|c|}{ Self-reported diagnosis or treatment in last 12 months } \\
\hline Diabetes & 93,408 & 0.5 & 0.2 & 0.5 & 0.5 & 0.5 & 0.3 & 0.97 \\
\hline Heart disease & 222,538 & 1.1 & 0.4 & 0.5 & 0.5 & 1.3 & 0.5 & 0.36 \\
\hline Hypertension & 347,169 & 1.7 & 1.0 & 2.1 & 1.2 & 1.6 & 1.2 & 0.79 \\
\hline Asthma & $2,002,763$ & 9.9 & 1.8 & 11.5 & 3.2 & 9.4 & 2.0 & 0.57 \\
\hline Depression & 136,807 & 0.7 & 0.3 & 2.2 & 1.1 & 0.2 & 0.2 & 0.00 \\
\hline Anxiety & $1,543,697$ & 7.6 & 1.5 & 9.3 & 2.5 & 7.1 & 1.8 & 0.47 \\
\hline Bipolar disorder & 72,075 & 0.4 & 0.2 & 1.3 & 0.9 & 0.1 & 0.1 & 0.00 \\
\hline Renal disease & 114,951 & 0.6 & 0.3 & 1.3 & 1.0 & 0.3 & 0.3 & 0.16 \\
\hline \multicolumn{9}{|l|}{ Substance use, lifetime } \\
\hline Tobacco & $1,267,767$ & 6.3 & 1.1 & 22.0 & 4.0 & 1.7 & 0.6 & 0.00 \\
\hline Benzodiazepines & 228,988 & 1.1 & 0.5 & 2.8 & 1.7 & 0.6 & 0.3 & 0.03 \\
\hline Amphetamines & 118,612 & 0.6 & 0.5 & 2.2 & 2.0 & 0.1 & 0.1 & 0.00 \\
\hline Barbiturates & 61,177 & 0.3 & 0.2 & 0.3 & 0.3 & 0.3 & 0.2 & 0.91 \\
\hline Opioids & 418,148 & 2.1 & 1.0 & 1.5 & 0.8 & 2.2 & 1.3 & 0.59 \\
\hline Inhalants & 222,550 & 1.1 & 0.4 & 2.9 & 1.3 & 0.6 & 0.3 & 0.01 \\
\hline Marijuana & 677,601 & 3.3 & 0.8 & 12.5 & 3.1 & 0.7 & 0.4 & 0.00 \\
\hline Cocaine & 234,275 & 1.2 & 0.4 & 4.9 & 1.7 & 0.1 & 0.1 & 0.00 \\
\hline
\end{tabular}


Table 1 (continued)

\begin{tabular}{|c|c|c|c|c|c|c|c|c|}
\hline \multirow[b]{3}{*}{ Variables } & \multirow{2}{*}{\multicolumn{3}{|c|}{ Overall }} & \multicolumn{4}{|c|}{ Underage drinking } & \multirow[b]{3}{*}{$p$-value ${ }^{\dagger}$} \\
\hline & & & & \multicolumn{2}{|c|}{ Yes } & \multicolumn{2}{|c|}{ No } & \\
\hline & Estimated population $(\mathrm{N})$ & $\%$ & SE & $\%$ & SE & $\%$ & SE & \\
\hline Ecstasy & 77,424 & 0.4 & 0.2 & 1.3 & 0.8 & 0.1 & 0.1 & 0.01 \\
\hline Injected drug use & 59,482 & 0.3 & 0.2 & 1.0 & 0.8 & 0.1 & 0.1 & 0.02 \\
\hline Any medication & 804,116 & 3.4 & 1.3 & 6.1 & 2.6 & 3.4 & 1.3 & 0.59 \\
\hline Any illicit drug & 813,557 & 4.0 & 0.8 & 13.9 & 3.2 & 1.2 & 0.5 & 0.00 \\
\hline Was threatened in last 12 months & $1,294,245$ & 6.4 & 1.2 & 9.9 & 2.9 & 5.4 & 1.3 & 0.10 \\
\hline Was beaten in last 12 months & 82,175 & 0.4 & 0.2 & 1.1 & 0.8 & 0.2 & 0.2 & 0.09 \\
\hline
\end{tabular}

$\mathrm{SE}=$ standard error.

$\chi^{2}$ with Rao-Scott adjustment.

Table 2 AOR for past 12-month alcohol use among youth between the ages of 12-17 years, Brazil, 2015

\begin{tabular}{|c|c|c|c|}
\hline \multirow[b]{2}{*}{ Variables } & \multirow[b]{2}{*}{ AOR } & \multicolumn{2}{|c|}{$95 \% \mathrm{Cl}$} \\
\hline & & Lower & Higher \\
\hline \multicolumn{4}{|l|}{ Sex } \\
\hline Male & 1.11 & 0.66 & 1.85 \\
\hline Female & Ref. & - & - \\
\hline \multicolumn{4}{|l|}{ Religion } \\
\hline Christian & Ref. & - & - \\
\hline Other (none/Catholic/others) & 2.55 & 1.52 & 4.29 \\
\hline \multicolumn{4}{|l|}{ Urban vs. rural } \\
\hline Urban & Ref. & - & - \\
\hline Rural & 2.29 & 1.30 & 4.04 \\
\hline \multicolumn{4}{|l|}{ Self-rated health } \\
\hline Very good/good & Ref. & - & - \\
\hline Fair/poor/very poor & 0.60 & 0.26 & 1.40 \\
\hline \multicolumn{4}{|l|}{ Tobacco use, lifetime } \\
\hline Yes & 13.27 & 5.14 & 34.27 \\
\hline No & Ref. & - & - \\
\hline \multicolumn{4}{|l|}{ Any illicit drug use, lifetime } \\
\hline Yes & 3.40 & 1.03 & 11.18 \\
\hline No & Ref. & - & - \\
\hline \multicolumn{4}{|c|}{ Self-reported diagnosis/treatment for depression in last 12 months } \\
\hline Yes & 8.79 & 1.03 & 74.72 \\
\hline No & Ref. & - & - \\
\hline
\end{tabular}

$95 \% \mathrm{Cl}=95 \%$ confidence interval; AOR = adjusted odds ratios; Ref. = reference category.

Hosmer-Lemeshow test $p$-value $=0.7925$.

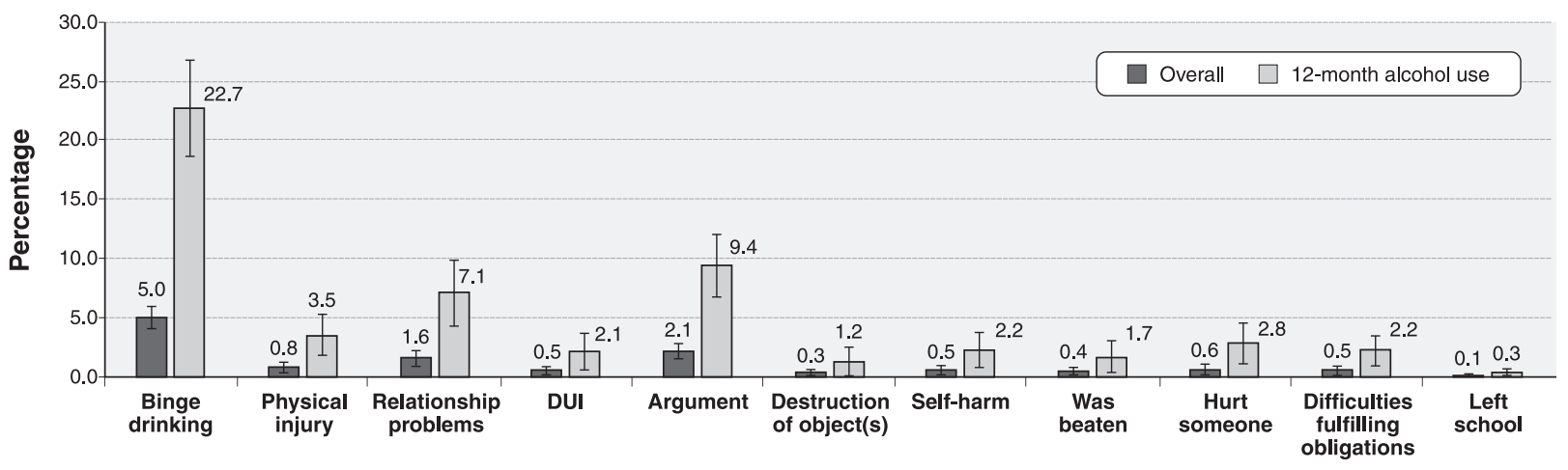

Figure 1 Alcohol-related problems among youth between the ages of 12-17 years, Brazil, 2015. DUI = driving under the influence. 
functional and cognitive deficits. ${ }^{5,6}$ Several risk factors for underage drinking have been identified, such as childhood physical abuse, parenting factors, peer influences, conduct problems, and depression., ${ }^{94,35}$ Fortunately, there is some evidence suggesting that the implementation of interventions including family-based prevention programs, mentoring, mHealth technology (e.g., mobile applications, social networking websites, text messages, etc.), and public health measures (e.g., restrictions on alcohol availability, taxation to increase prices, etc.) can prevent or reduce alcohol use among adolescents. ${ }^{36-39}$ A recent study of adolescents of 11-17 years in the United Kingdom demonstrated that positive reactions to alcohol advertisements were associated with an increased susceptibility to underage drinking for those with no history of alcohol use, and with high-risk drinking for current alcohol users. ${ }^{40}$ This indicates that regulation of alcohol advertisements may also help to inhibit underage drinking. A Brazilian study found, through the use of machinelearning algorithms, that driving under the influence of alcohol was associated with male sex, binge drinking, and past-year drug use. ${ }^{41}$ This indicates the promising potential of machine-learning techniques to inform policymaking and the implementation of targeted interventions through the prompt identification of individuals that are at a particularly high risk of facing the adverse outcomes associated with adolescent alcohol consumption in Brazil.

The findings of the present study should be considered in light of some limitations. One limitation was the crosssectional design of this study, which precludes any inference of causality. Another limitation was the use of self-report assessments, which may be a source of social desirability bias. Furthermore, parenting style regarding alcohol use was not evaluated, which is a known contributing factor to adolescent alcohol use. ${ }^{42}$ Despite these limitations, several strengths of this study are worth highlighting. First, this study used a probability sample, which allows generalizability of the findings to the entire Brazilian population at this age. Additionally, a wide variety of factors were examined, including sociodemographic characteristics, medical conditions, the use of illicit substances, and alcohol-related problems, enabling an extensive investigation of the factors associated with underage drinking.

Overall, the main findings of this study demonstrate the high prevalence of alcohol use among Brazilian youth, as well as the alarming alcohol-related problems (e.g., binge drinking, physical injury, relationship problems, driving under the influence of alcohol, etc.) associated with underage drinking in this population. Other known consequences of underage drinking include deficits in cognition and brain development, difficulties with interpersonal relationships, and academic issues. The present study found several risk factors for alcohol use among Brazilian adolescents, such as residing in rural areas, selfreporting a diagnosis of depression, tobacco use, any illicit drug use, and having no/other religion in comparison to Christianity. Identification of such risk factors for adolescent alcohol use will enable the timely implementation of suitable interventions among those who are at the highest risk of underage drinking. The early implementation of interventions and public health measures focused on the prevention or reduction of adolescent alcohol consumption may be promising to limit the devastating consequences of underage drinking in Brazil.

\section{Acknowledgements}

The authors would like to thank the FIOCRUZ and the SCIENCE (Sociedade para o Desenvolvimento da Pesquisa Científica) teams, as well as all the respondents who participated in the surveys. This study was funded by different Brazilian government agencies: the original survey was funded by a contract with Secretaria Nacional de Políticas sobre Drogas (SENAD; Federal decree 7.179, May 10, 2010). New analyses were carried out in the context of the "Analysis/reanalysis of Brazilian major databases on substance use" component of Fundação de Amparo à Pesquisa do Estado do Rio de Janeiro (FAPERJ) Health Network program grant (E-26/ $010.002428 / 2019$ ), coordinated by FIB. JCM is a senior statistician of the FAPERJ network. TAC acknowledges her postdoctoral fellowship from the Canadian Institutes of Health Research (CIHR). FIB is a career scientist at Conselho Nacional de Desenvolvimento Científico e Tecnológico (CNPq). FK has received grants from Instituto Nacional de Ciência e Tecnologia Translacional em Medicina (Fundação de Amparo à Pesquisa do Estado de São Paulo [FAPESP] 2014/50891-1 and CNPq 465458/2014-9), Fundação de Amparo à Pesquisa do Estado do Rio Grande do Sul (FAPERGS; 20125510000250.0), the Canada Foundation for Innovation (CFI), the Social Sciences and Humanities Research Council (SSHRC), the CIHR, and the Natural Sciences and Engineering Research Council (NSERC). RBDB has received grants from the CNPq (312543/2020-4) and FAPERJ (E-26/203.154/2017).

\section{Disclosure}

FK has received personal fees as a speaker/consultant from Janssen-Johnson \& Johnson. The other authors report no conflicts of interest.

\section{References}

1 Ryan SA, Kokotailo P, Committee on Substance Use and Prevention. Alcohol use by youth. Pediatrics. 2019;144:e20191357.

2 Johnston LD, Miech RA, O'Malley PM, Bachman JG, Schulenberg $\mathrm{JE}$, Patrick ME. Monitoring the future national survey results on drug use, 1975-2018: overview, key findings on adolescent drug use [Internet]. 2019 [cited 2021 Sep 17]. eric.ed.gov/?id=ED604018

3 National Institute on Alcohol Abuse and Alcoholism (NIAAA). Alcohol facts and statistics [Internet]. [cited $2021 \mathrm{Apr}$ 15]. www.niaaa.nih.gov/ publications/brochures-and-fact-sheets/alcohol-facts-and-statistics

4 Barbosa Filho VC, de Campos W, da Silva Lopes A. Prevalence of alcohol and tobacco use among Brazilian adolescents: a systematic review. Rev Saude Publica. 2012;46:901-17.

5 Lees B, Meredith LR, Kirkland AE, Bryant BE, Squeglia LM. Effect of alcohol use on the adolescent brain and behavior. Pharmacol Biochem Behav. 2020;192:172906. 
6 Spear LP. Effects of adolescent alcohol consumption on the brain and behaviour. Nat Rev Neurosci. 2018;19:197-214.

7 Guo L, Deng J, He Y, Deng X, Huang J, Huang G, et al. Alcohol use and alcohol-related problems among adolescents in China: a large-scale cross-sectional study. Medicine (Baltimore). 2016;95: e4533.

8 Popovici I, Homer JF, Fang H, French MT. Alcohol use and crime: findings from a longitudinal sample of U.S. adolescents and young adults. Alcohol Clin Exp Res. 2012;36:532-43.

9 Yuen WS, Chan G, Bruno R, Clare P, Mattick R, Aiken A, et al. Adolescent alcohol use trajectories: risk factors and adult outcomes. Pediatrics. 2020;146:e20200440.

10 Boden J, Blair S, Newton-Howes G. Alcohol use in adolescents and adult psychopathology and social outcomes: findings from a 35-year cohort study. Aust N Z J Psychiatry. 2020;54:909-18.

11 Blum RW, Bastos FI, Kabiru CW, Le LC. Adolescent health in the 21st century. Lancet. 2012;379:1567-8.

12 Jadhav KS, Boutrel B. Prefrontal cortex development and emergence of self-regulatory competence: the two cardinal features of adolescence disrupted in context of alcohol abuse. Eur $\mathrm{J}$ Neurosci. 2019;50:2274-81.

13 Jones SA, Lueras JM, Nagel BJ. Effects of binge drinking on the developing brain. Alcohol Res. 2018;39:87-96.

14 National Institute on Alcohol Abuse and Alcoholism (NIAAA). NIAAA council approves definition of binge drinking [Internet]. 2004 [cited 2021 Sep 17]. pubs.niaaa.nih.gov/publications/Newsletter/winter2004/ Newsletter_Number3.pdf

15 Coutinho ES, França-Santos D, da Silva Magliano E, Bloch KV, Barufaldi LA, De Freitas Cunha C, et al. ERICA: patterns of alcohol consumption in Brazilian adolescents. Rev Saude Publica. 2016; 50 Suppl:8s.

16 Krawczyk N, Silva PL, De Boni RB, Mota J, Vascncellos M, Bertoni N, et al. Non-medical use of opioid analgesics in contemporary Brazil: findings from the 2015 Brazilian National Household Survey on Substance Use. Global Public Health; 2019.

17 De Boni RB, de Vasconcellos MT, Silva PN, Coutinho C, Mota J, Peixoto JN, et al. Reproducibility on science: challenges and advances in Brazilian alcohol surveys. Int $\mathrm{J}$ Drug Policy. 2019;74:285-91.

18 Bertoni N, Szklo A, De Boni R, Coutinho C, Vasconcellos M, Nascimento Silva $P$, et al. Electronic cigarettes and narghile users in Brazil: do they differ from cigarettes smokers? Addict Behav. 2019;98:106007.

19 De Boni RB, de Vasconcellos MT, Pedro Luis NS, Silva KM, Bertoni $\mathrm{N}$, Coutinho CF, et al. Substance use, self-rated health and HIV status in Brazil. AIDS Care. 2021;33(10):1358-62.

20 Instituto de Comunicação e Informação Científica e Tecnológica em Saúde (ICICT), Fundação Oswaldo Cruz (Fiocruz). 3rd national survey on drug use by the Brazilian population [Internet]. 2017 [cited 2021 Sep 21]. www.arca.fiocruz.br/bitstream/icict/34614/2/III\%20LN UD_ENGLISH.pdf

21 Brasil, Presidencia da Republica. Lei 13.106. Diário Oficial da União, 17 março 2015. www.planalto.gov.br/ccivil_03/_ato2015-2018/2015/ lei//13106.htm

22 Instituto Brasileiro de Geografia e Estatística (IBGE). Censo demográfico 2010. censo2010.ibge.gov.br/resultados.html

23 Idler EL, Benyamini Y. Self-Rated health and mortality?: a review of twenty-seven community studies. J Health Soc Behav. 1997;38:21-37.

24 Rao JN, Scott AJ. On chi-squared tests for multiway contingency tables with proportions estimated from survey data. Ann Statist. 1984;12:46-60.

25 Lumley T. Complex surveys: a guide to analysis using R. Wiley Series in Survey Methodology. Hoboken: John Wiley \& Sons; 2010.
26 Substance Abuse and Mental Health Services Administration (SAMHSA). Results from the 2018 national survey on drug use and health: detailed tables [Internet]. [cited 2021 Apr 24]. www.samhsa. gov/data/sites/default/files/cbhsq-reports/NSDUHDetailedTabs2018 R2/NSDUHDetailedTabs2018.pdf

27 Canada, Government of Canada. Summary of results for the Canadian student tobacco, alcohol and drugs survey 2018-19 [Internet]. [cited 2021 Apr 24]. www.canada.ca/en/health-canada/services/ canadian-student-tobacco-alcohol-drugs-survey/2018-2019-summary. html

28 Donath C, Gräßel E, Baier D, Pfeiffer C, Karagülle D, Bleich S, et al. Alcohol consumption and binge drinking in adolescents: comparison of different migration backgrounds and rural vs. urban residence a representative study. BMC Public Health. 2011;11:84.

29 Charro Baena B, Meneses C, Caperos JM, Prieto M, Uroz J. The role of religion and religiosity in alcohol consumption in adolescents in Spain. J Relig Health. 2019;58:1477-87.

30 Griffin KW, Lowe SR, Botvin C, Acevedo BP. Patterns of adolescent tobacco and alcohol use as predictors of illicit and prescription drug abuse in minority young adults. J Prev Interv Community. 2019; 47:228-42.

31 Boden JM, Fergusson DM. Alcohol and depression. Addiction. 2011; 106:906-14.

32 Andrade SS, Yokota RT, de Sá NN, da Silva MM, de Araújo WN, Mascarenhas MD, et al. [Association between physical violence, consumption of alcohol and other drugs, and bullying among Brazilian adolescents]. Cad Saude Publica. 2012;28:1725-36.

33 Chung T, Creswell KG, Bachrach R, Clark DB, Martin CS. Adolescent binge drinking. Alcohol Res. 2018;39:5-15.

34 de Moraes CL, de Freitas Ferreira M, Reichenheim ME, Gaudard E Silva A, Valéria da Veiga G. Pathways linking childhood physical abuse to alcohol misuse in adolescent boys and girls: a prospective cohort study from Rio de Janeiro, Brazil. J Stud Alcohol Drugs. 2020; 81:362-71.

35 Isaksson J, Schwab-Stone M, Stickley A, Ruchkin V. Risk and protective factors for problematic drinking in early adolescence: a systematic approach. Child Psychiatry Hum Dev. 2020;51:231-8.

36 Byrnes HF, Miller BA, Grube JW, Bourdeau B, Buller DB, WangSchweig M, et al. Prevention of alcohol use in older teens: a randomized trial of an online family prevention program. Psychol Addict Behav. 2019;33:1-14

37 Thomas RE, Lorenzetti DL, Spragins W. Systematic review of mentoring to prevent or reduce alcohol and drug use by adolescents. Acad Pediatr. 2013;13:292-9.

38 Hutton A, Prichard I, Whitehead D, Thomas S, Rubin M, Sloand E, et al. mHealth interventions to reduce alcohol use in young people: a systematic review of the literature. Compr Child Adolesc Nurs. 2020;43:171-202.

39 Alcohol and Public Policy Group. Alcohol: no ordinary commodity a summary of the second edition. Addiction. 2010;105:769-79.

40 Boniface S, Critchlow N, Severi K, MacKintosh AM, Hooper L, Thomas C, et al. Underage adolescents' reactions to adverts for beer and spirit brands and associations with higher risk drinking and susceptibility to drink: a cross-sectional study in the UK. Alcohol Alcohol. 2021 Apr 23;agab018. doi:10.1093/alcalc/agab018. Online ahead of print.

41 Rabelo-da-Ponte FD, Scherer JN, Roglio V, Borges EN, Galland F, Sousa $\mathrm{T}$, et al. From phone use to speeding and driving under influence: identifying clusters of driving risk behaviors as an opportunity for targeted interventions. J Psychiatr Res. 2021;143:556-62.

42 Zuquetto CR, Opaleye ES, Feijó MR, Amato TC, Ferri CP, Noto AR. Contributions of parenting styles and parental drunkenness to adolescent drinking. Braz J Psychiatry. 2019;41:511-7. 